\section{ONOMAREDIN}

Revista semestral de lingüística, filología y traducción
PONTIFICIA UNIVERSIDAD CATÓLICA DE CHILE CATOLICA DE CHILE
FACULTAD DE LETRAS

\title{
Comprensión oral de narraciones y producción narrativa: dos medidas a través de una tarea de recontado ${ }^{1}$
}

Oral comprehension and production of narratives: Two retelling task measurements

\section{Andrea Bustos Ibarra}

Pontificia Universidad Católica de Valparaíso

Chile

\section{Nina Crespo Allende}

Pontificia Universidad Católica de Valparaíso Chile

\section{(C) $\underset{\mathrm{BY}}{ } \bigodot_{\mathrm{ND}}$}

Andrea Bustos Ibarra: Escuela de Pedagogía, Facultad de Filosofía y Educación, Pontificia Universidad Católica de Valparaíso, Chile. | Correo electrónico: andrea.bustos@ucv.cl

Nina Crespo Allende: Instituto de Literatura y Ciencias del Lenguaje, Facultad de Filosofía y Educación, Pontificia Universidad Católica de Valparaíso, Chile. | Correo electrónico: ncrespo@ucv.cl 


\section{Resumen}

La investigación del desarrollo de la producción oral en la infancia requiere de un diseño metodológico que permita controlar consistentemente las tareas. Este estudio se propone analizar en la técnica de recontado la incidencia que tiene la comprensión de un relato en su elicitación. Para ello, plantea medir el nivel de comprensión y la calidad del recontado que tienen 31 niños de kínder de 5 años de un cuento infantil de dos episodios (Stein y Glenn, 1979; Owens, 1991). La aplicación del recontado introdujo algunos elementos para optimizar la tarea (Reese y otros, 2012). Inicialmente, cada participante en forma individual vio una versión audivisual del cuento y, a continuación, recontó oralmente dicho cuento con apoyo gráfico (Reese y otros, 2012). Los sujetos respondieron posteriormente a preguntas de comprensión, elaboradas siguiendo el modelo propuesto por Pavez y otros (2008).

Los textos orales transcritos fueron evaluados con indicadores de producción oral, basados en la propuesta de Petersen y otros (2008). Los resultados permiteron describir el perfil de comprensión que poseen los niños de un cuento y su producción oral, al diferenciar medidas de rasgos propios de la riqueza narrativa. Ambas medidas arrojan resultados diferenciados estadísticamente que permiten afirmar que la capacidad de comprensión del cuento, si bien es necesaria para el recontado, no se correlaciona con la riqueza narrativa del relato.

Palabras clave: recontado; comprensión oral; producción oral; narraciones.

\section{Abstract}

Research on the development of oral production in childhood requires a methodological design that allows controlling tasks and variables consistently. This study aims to analize the retelling technique as well as the incidence of the oral comprehension in stories elicitation. In order to do this, we measured the comprehension level in a sample of thirty one five-year-old children through a retelling of a two episodes story (Stein \& Glenn, 1979; Owens, 1991). In the application of the retelling technique we introduced two new elements to optimize the task (Reese et al., 2012). Initially, each participant individually saw an audiovisual version of the story and, secondly, then they retold this story orally with a picture book (Reese et al., 2012). Subjects then answered comprehension questions, following Pavez et al. model (2008). Transcriptions of the oral texts were assesed with oral production's indicators, based on Petersen et al. (2008) proposal. The results allowed to describe the profile of children's comprehension of a story and their narrative oral production, pointing at the different features of narrative richness. Both measures lead to statistically different results, that support the conclusion that the ability to comprehend the story, although it seems necessary for retelling, it does not correlate with richness of the story produced by children.

Keywords: retelling; oral comprehension; oral production; narratives. 


\section{Introducción}

Autores como Owens (1991) y Botting (2002) indican la importancia de la narrativa para medir el desarrollo del lenguaje infantil, ya sea que se trate de un desarrollo típico o no. Los autores señalan que dicha modalidad discursiva es autogestionada, por lo que puede considerársela más compleja que la conversación espontánea, a pesar de que es accesible a los niños y se encuentra en sus ámbitos de interacción. Asimismo, Acosta y otros (2011) señalan que la modalidad narrativa resulta un aspecto esencial para los niños tanto para interactuar socialmente como para comprender el mundo que los rodea, a la vez que representa un recurso privilegiado para enfrentarse con cierto éxito al proceso de alfabetización

Una técnica para elicitar el discurso narrativo en los pequeños es el recontado. Este es un estudio que puede ubicarse, de acuerdo con Eisenbeiss (2010), entre las técnicas semiestructuradas y reviste dos ventajas. Por un lado, el control del estímulo que se da en ellas permite comparar las respuestas de los participantes en el estudio (no podría hacerse si fueran historias espontáneas) y, por otro, son ecológicamente más válidas que las tareas experimentales, por encontrarse más cerca de las vivencias habituales de los niños (la narración de historias es algo que ocurre frecuentemente en los ámbitos escolares).

Ahora bien, el recontado como herramienta metodológica no está exento de limitaciones, ya que es una tarea de doble faz: mide la producción oral, pero se trata de una producción basada en la comprensión del estímulo inicial. A este respecto, Skehan y Foster (1999) señalan que la estructura inherente de la tarea y la carga del procesamiento que tiene el sujeto al captar el estímulo oralmente pueden afectar la fluidez, la precisión y la complejidad del discurso producido. Por ello, interesa aquí ir más allá: es necesario conocer cuál es el nivel de comprensión que los niños tienen de un determinado texto y observar posibles relaciones con la calidad del discurso recontado. Sin detenernos en esta cuestión, es posible concluir que un determinado nivel de habilidad para narrar que exhibe el sujeto responde a una variable de producción, cuando en realidad dicha variable está condicionada por el procesamiento del input inicial.

Teniendo en cuenta esta problemática, el presente estudio se propone dilucidar cuál es realmente la incidencia que tiene la comprensión de un determinado relato en la calidad de la producción del discurso que elicita un niño. Por este motivo, se propone observar el nivel de comprensión que niños de 5 años tienen de un cuento infantil de dos episodios (Stein y Glenn, 1979) presentado en formato audiovisual y relacionarlo con la calidad del recuento que realizan. El artículo se organiza de la siguiente manera: en primer lugar, se presenta el marco teórico, donde se exponen los antecedentes del recontado y de la medición de calidad de la producción oral. En segundo lugar, se detalla la metodología, que da cuenta de los sujetos, los materiales y las técnicas de investigación. Finalmente, se presentan los resultados y la discusión final de los hallazgos.

\section{Marco teórico}

Gillam y Pearson (2004) describen las narraciones como historias acerca de eventos reales o imaginarios que son construidos uniendo enunciados acerca de contextos situacionales, personajes, acciones, motivaciones, emociones y resultados. Esta modalidad discursiva es un vehículo importante para el aprendizaje académico, social, lingüístico y cultural. Al respecto, Acosta y otros (2011) señalan que los niños usan una amplia variedad de géneros narrativos y lo hacen para cumplir múltiples propósitos, entre ellos, relacionar eventos, establecer y mantener relaciones de amistad y expresar sus pensamientos y sentimientos acerca de tópicos importantes (McCabe y Bliss, 2004). Así, empiezan elaborando narraciones autobiográficas acerca de sus experiencias pasadas, hecho que sucede desde 
el inicio de los tres años de edad. A continuación, utilizan guiones en los que se describen acciones en forma de rutinas ordenadas, siguiendo unos criterios temporales y lógicos (por ejemplo, "La visita al doctor"). Por último, se presenta la denominada narración ficticia, propiciada en situaciones donde suele ser habitual el manejo y la lectura de libros.

En el ámbito del estudio y la evaluación del lenguaje, la elicitación de narraciones puede variar según sean los fines para los cuales se lleva esta recolección. Así, si un investigador busca una caracterización de rasgos generales en una variante lingüística, de acuerdo a variables intrasujeto como clase social, edad o género, propondrá una narración espontánea, en la que el sujeto utilice el lenguaje sin estímulos ni condicionamientos. Este es el caso de propuestas que vienen desde la sociolingüística o desde estudios de ontogenia del lenguaje. Entre las primeras propuestas estarían aquellas basadas en Labov y Waletzky (1967), como la de Guerrero (2011). Para las que indagan en la ontogenia, cabe citar trabajos como el de Cavalcante y Mandrá (2010).

Por otra parte, como es el caso de este estudio, el investigador puede proponer un estímulo más controlado, sin llegar al extremo de un ámbito experimental (Eisenbeiss, 2010). Aquí, el investigador buscará reunir tanto la espontaneidad del discurso como la homogeneidad del estímulo original, lo que le permitirá comparar el desempeño de diversos sujetos e incluso de diversas poblaciones. De esta manera, pedirá al sujeto que cree una narración ficticia a partir de algún estímulo pictórico, como es el caso del cuento Frog, where are you, utilizado profusamente en la investigación del desarrollo narrativo oral en niños (Slobin, 2004). Otras veces, como es el caso de Pavez y otros (2008), el estímulo del relato se propone oralmente al niño y se le solicita reproducirlo. Esta tarea de narración de eventos ficticios, partiendo de un estímulo, se ha denominado recontado. Mandel Morrow (1986: 136) la define como "a postreading or listening recall in which children tell what they remember from their reading or listening" (la evocación posterior a una lectura o audición en la cual los niños dan cuenta del recuerdo de lo leído o escuchado). En este caso, el sujeto construye su discurso libremente pero lo hace sobre la base de un recuerdo de algo leído, escuchado o visto. La ventaja indudable de esta técnica es que les otorga a los investigadores algún tipo de control sobre la estructura y trama del contenido general de los relatos de los niños (Petersen y otros, 2008).

Estas condiciones en las que tiene lugar el recontado pueden ejercer una influencia en el discurso final que los sujetos en estudio produzcan. Tanto la disponibilidad y tipo de materiales (narración de otro, imágenes, video) como el tipo de exposición (narración más imágenes) y la condición de recontado (con o sin narración previa, utilizando imágenes, utilizando un video, sin apoyo) pueden tener efectos en la narración. Así, Schneider (1996) aplicó a un grupo de niños con problemas de lenguaje, entre los 5 y los 10 años, diferentes formatos para elicitar tareas de recontado y descubrió que las mejores producciones - en término de cantidad de episodios y unidades de información- fueron las elaboradas por niños que solo escucharon las historias. Las narraciones que se produjeron a partir solo de las imágenes tenían menos información desde el punto de vista de la gramática de las historias, más información extraña y menos marcadores formulaicos. Podría decirse que la tarea de recontar es más fácil que la narración espontánea, pues la presencia de una narración de otro que puede ser vista y escuchada - permite una anticipación de la estructura, que, al momento del recontado, es relevante (Meyer, 1985), puesto que permite reconstruir el contenido a partir de estas claves retóricas facilitadas oralmente por el narrador con su correspondiente prosodia y que, por lo tanto, no deben ser activadas por parte del sujeto de manera autónoma (García y otros, en prensa).

Por otra parte, el estudio de Skehan y Foster (1999) tuvo como propósito valorar la calidad de la producción narrativa de adultos en tareas de 
recontado, utilizando las variables de fluidez, en tanto capacidad de usar el lenguaje en tiempo real, de enfatizar significados recurriendo a sistemas más lexicalizados; la precisión, entendida como la capacidad de evitar el error en el rendimiento, y la complejidad, como la capacidad de usar el lenguaje sintácticamente más elaborado, medido a través de las unidades T propuestas por Kellog Hunt (1972). Los resultados arrojaron que los sujetos distribuían diferencialmente la atención entre la fluidez, la precisión y la complejidad del discurso que debían recontar, dependiendo de cuatro condiciones: en la primera los sujetos debían ver un relato visual y contarlo simultáneamente (más exigente cognitivamente, pues debían narrar una historia que no conocían de antemano); la segunda consistía en que se les resumía oralmente la historia y luego, mientras se les mostraban un grupo de las ilustraciones relacionadas con esta, debían narrarla (menos demandante por conocimiento previo); en la tercera, el participante veía un video con la historia completa, vuelve a ver el video sin sonido y lo narra simultáneamente (más fácil que el anterior pues tiene los detalles de la historia), y, por último, el sujeto ve el video y luego lo narra espontáneamente, sin tener que atenerse a imágenes externas.

A partir de allí, los autores concluyeron que las tareas que contenían más clara la estructura secuencial inherente (como las que daban el resumen o la vista previa del texto) daban lugar a un funcionamiento más fluido que las tareas no estructuradas de esta manera. Parecería que ser capaz de acceder a la macroestructura de una tarea disminuye la necesidad de participar en una gran cantidad de semitareas de reparación. Así, el plan general que está disponible permite a los participantes asignar atención al lenguaje de una manera más sostenida. Es como si los procesos de planificación, y la delegación de la atención a los problemas de planificación local, pudieran lograrse con mayor eficacia. Sin embargo, este conocimiento de la estructura secuencial no tuvo efectos totales en la exactitud o precisión del discurso producido. Solo la cuarta condición, en la cual el sujeto miraba la historia y luego la contaba sin atenerse a un elemento externo, pareció favorecer la exactitud o precisión de su recuento. Asimismo, las condiciones que exigían más procesamiento afectaron el nivel de complejidad sintáctica del texto recontado por el sujeto.

En otro estudio, Gazella y Stockman (2003) e Isbell y otros (2004) investigaron si la modalidad de la presentación de la historia influenciaba en el texto producido por niños. Gazella y Stockman (2003) observaron que presentar un texto en forma oral o en forma audiovisual no producía diferencias significativas en la cantidad de habla, la diversidad léxica y la complejidad de las oraciones, cuando niños de 4,2 y 5,6 años recontaban una historia o respondían a preguntas acerca de su contenido. A pesar de esto, se encontró que la condición audiovisual favorecía que la tarea de recontado se hiciera con oraciones más largas y más complejas gramaticalmente. Por su parte, Isbell y otros (2004) quisieron determinar cómo se veía influenciado el recontado de una historia en niños preescolares si esta se les presentaba narrada oralmente o leída en un libro de cuentos. Los niños debían recontar la historia que habían escuchado, apoyándose en un libro de láminas. Se observó que las dos condiciones de presentación de la historia producían una ganancia en el lenguaje oral del niño. No obstante, para estos autores, los niños más pequeños que escuchaban la historia la habían comprendido mejor y esto lo reflejaban en su recontado, mientras que los que escuchan el texto leído parecen evidenciar un lenguaje más complejo en sus propias producciones.

Westerveld (2011), por su lado, presenta tres experimentos que investigan qué influencia tienen, en el recontado y el recuerdo, las variaciones de la administración del estímulo inicial, las cuales pueden ser: el tipo de exposición al modelo de la historia (verbal o verbal y visual), 
el momento de las preguntas de comprensión (antes o después de que el niño recuente) y la presencia o ausencia de las imágenes durante la narración de la historia. Los resultados de este estudio sugieren que dichas variaciones en las condiciones de trabajo relacionadas con el tipo de exposición, la cantidad de la exposición o la presencia/ausencia de apoyo de imagen durante la narración de la historia no afectarán el rendimiento de los niños en sintaxis. Finalmente, la autora concluye que la presencia de las imágenes durante la narración es la única variable que influye en el rendimiento, en las medidas de la productividad verbal y en fluidez verbal de los niños.

Ahora bien, un punto relevante dentro del estudio de Westerveld (2011) es el de demostrar que exponer dos veces al niño al estímulo (una a través del narrado y otra a través de preguntas de comprensión previas al recontado) no impactaba en su narración. En otras palabras, a pesar de que el recontado de un texto narrativo es una tarea de productividad basada en el recuerdo y que una doble exposición hipotéticamente mejoraría la comprensión y el recuerdo del texto fuente, este hecho no parece afectar la productividad oral del niño. Dada la naturaleza de esta tarea, es lícito pensar que si el niño no comprende - logra almacenar la información del estímulo narrativo (ya sea verbal, audiovisual o visual), lo más probable es que no pueda narrarlo. Por ello, es muy importante el apoyo con imágenes al recontar para disminuir la carga cognitiva y el impacto del recuerdo. Sin embargo, no es posible señalar que el nivel que el niño logre en la comprensión del texto fuente afecta directamente en la calidad del texto que el niño produzca.

Respecto de este nudo, "comprensión - calidad de la producción oral", autoras como Pavez y otros (2008) han controlado la comprensión que los sujetos tenían del cuento, cuando implementaban una tarea de recontado; de esta manera han probado que todos los niños -independientemente del nivel de productividad narrativa - logran una comprensión aceptable del estímulo. La propuesta de este trabajo es ir más allá: proponemos plantear que la productividad de un texto en la tarea de recontado puede medirse en forma independiente del nivel de comprensión que el niño exhiba del estímulo inicial. En resumen, consideramos que, dada la naturaleza del recontado, la comprensión por parte del niño del cuento que se presenta para recontar es necesaria e indispensable, pero esta mera comprensión no basta para explicar el nivel de productividad que alcanza en el discurso narrativo. Por este motivo, dicha productividad debe medirse como algo distinto de la comprensión. Esta última podría evaluarse observando qué elementos del texto fuente del recontado aparecen representados en el texto elaborado por el niño, ya sea a través del conteo de ideas (Reese y otros, 2012) o a través de preguntas de nivel literal e inferencial (León y Marchesi, 1987). La productividad, en cambio, debe medirse considerando la calidad de los elementos utilizados $y$, a partir de allí, elaborar una propuesta que nos permita estimar el nivel de elaboración que tienen. Esto es lo que Justice y otros (2006) y luego Petersen y otros (2008) Ilaman evaluación por criterio. Según estos autores, un procedimiento comúnmente referido a criterios para analizar contenido, forma y uso del lenguaje es el análisis de la muestra de lenguaje (Brown, 1973; Balason y Dollaghan, 2002). Este procedimiento es especialmente útil para evaluar la presencia o ausencia de las estructuras lingüísticas específicas y dar cuenta de cómo estas estructuras interactúan en el discurso. Incluye métodos que pueden ser usados para estandarizar cómo se recogen, transcriben y anotan muestras de lenguaje, para permitir la comparación de varios puntos en el tiempo. Concretamente, el índice (INC) presentado por Petersen y otros (2008) integra investigaciones existentes y enfoques conceptuales y analíticos relacionados con la evaluación de aspectos macro- y micorestructurales de la narrativa oral. El punto más importante está en el análisis de Labov y Waletzky (1967), la gramática 
de Stein y Glenn (1979) y los refinamientos de Peterson y McCabe (1983).

El sistema de puntaje del INC incluye categorías para evaluar la complejidad de trece aspectos de las narraciones. Los autores señalan que dichos aspectos tienen un peso diferente respecto de la complejidad episódica y la cohesión narrativa; así, los personajes, el evento inicial, el plan y las consecuencias son evaluados entre o y 3 puntos, mientras que la ubicación, la respuesta interna, la acción, la complicación, los marcadores formulaicos, los marcadores temporales, las cláusulas adverbiales causales, el diálogo y la evaluación puntean entre o y 2 puntos. Petersen y otros (2008) afirman que esta diferencia de peso en los puntajes fue diseñada para reflejar la relativa importancia de la contribución de cada elemento para el estilo narrativo de la cultura académica predominante que el niño debía dominar

Cuando los terapeutas desean saber si un niño ha hecho progresos durante la intervención, necesitan un sistema de puntajes que sea sensible a los cambios incrementales en las habilidades para la producción narrativa. El INC incorpora un sistema incremental de puntajes tal que las más altas puntuaciones reflejan la aparición de una narrativa más compleja. El estudio de Petersen y otros (2008) probó validez y confiabilidad con 20 niños con problemas de lenguaje en un esquema pretest-intervención-postest. Este tipo de enfoque evaluativo posee una doble virtud. Por un lado, permite evaluar no solo la presencia de los elementos de la narración (como lo haría la comprensión), sino que destaca la elaboración de los diversos elementos relacionados con la calidad del texto narrado. Incluso podría ocurrir que el sujeto incorporara detalles que no estaban en la historia original, aunque serían plausibles dentro de ella y esto valiera en su puntaje. Es más, el niño podría equivocarse en el nombre de los personajes, pero aun así recibir el máximo puntaje que refiere a la identificación de este con un nombre propio. En esta línea de evaluación de criterio no importa la repetición de elementos exactos del cuento, sino la complejidad en la construcción narrativa que el niño evidencia. Por otra parte, este enfoque incremental permite llevar a cabo un estudio longitudinal, en el cual se mida el rendimiento narrativo de un niño en diversos momentos de su vida, incluso sin que el sujeto haya recibido ningún tipo de tratamiento. Esta implementación es la que se propone en la investigación general que incluye este experimento.

\section{Metodología}

\subsection{Muestra}

La muestra estuvo constituida por 31 sujetos que asistían a establecimientos particulares subvencionados de la región de Valparaíso, Chile. Las edades fluctuaban entre los 5 años y 5 años 11 meses, pertenecientes al nivel NT2, kínder de educación parvularia. En la tabla 1 se consignan las distribuciones por género.

TABLA 1

Sujetos de la muestra

\begin{tabular}{c|c|c|c} 
SUJETOS & NIÑOS & NIÑAS & TOTAL \\
\hline N & 13 & 18 & 31 \\
\hline
\end{tabular}

\subsection{Procedimiento. Materiales aplicados}

\subsubsection{Tarea de recontado}

El procedimiento aplicado correspondió a una tarea de recontado de una narración creada para este estudio: "La Mariposa Flopi”, con una estructura de dos episodios. La propuesta sigue, por una parte, la gramática de las historias de Stein y Glenn (1979), reformada por Peterson y McCabe (1983) y posteriormente por Owens (1991), y, por otra, el modelo aplicado por Pavez y otros (2008). En la tabla 2 se presenta la estructura y los elementos del cuento resumidos.

La tarea consistió en la recepción de La Mariposa Flopi en formato audiovisual, a través de una presentación digital (voz grabada e imágenes estáticas). Una segunda fase consistió en la 


\section{TABLA 2}

Categorías de gramática de las historias de La Mariposa Flopi

\begin{tabular}{c|c|c} 
MOMENTO & DESCRIPCIÓN & ELEMENTOS DEL CUENTO \\
\hline Establecimiento de la escena & $\begin{array}{c}\text { Personaje / acción habitual } \\
\text { / tiempo y espacio }\end{array}$ & $\begin{array}{c}\text { Flopi / jugaba con amigas } \\
\text { / en el campo }\end{array}$ \\
\hline Evento inicial & $\begin{array}{c}\text { Acción nueva } \\
\text { Problema o quiebre }\end{array}$ & Van al campo de Don Bigotes \\
\hline Respuesta interna & Reacción (emocional o mental) & Don Bigotes se enoja \\
\hline Plan & Pasos previos para la meta & Persigue mariposas \\
\hline Intento & Pasos concretos & Atrapa a Flopi y encierra en frasco red \\
\hline Consecuencia evento inicial & Logro o no logro de la meta & Amigas hablan del rescate \\
\hline Respuesta interna & Amigas rescatan \\
\hline Plan & & Escapan de la casa de Don Bigotes \\
\hline Resolución y conclusión & Mariposas deciden no volver. \\
\hline
\end{tabular}

manipulación, por parte de los participantes, de una versión en papel de las mismas imágenes secuenciadas en formato de libro de cuento (sin acceso a texto verbal), elaborado según las propuestas de la gramática visual de Kress y Van Leeuwen (1996), para recontar a un segundo examinador, quien solicitaba la tarea como algo novedoso por estar fuera de la primera parte de la sesión. La tercera fase de la tarea consistió en responder a un listado de 9 preguntas de comprensión (6 literales, 3 inferenciales) a solicitud de este segundo examinador para poder "aprender bien el cuento". Toda la interacción fue aplicada en una sola sesión individual registrada en video y transcrita para los análisis de comprensión oral y producción narrativa.

\subsubsection{Evaluación de la producción}

En la evaluación del texto elaborado por el niño, se aplicó una escala de criterio similar a la propuesta por Justice y otros (2006) y reelaborada por Petersen y otros (2008). Sin embargo, las 13 categorías fueron reducidas a 10: Personaje (referencia a un sujeto en la narración), Localización (alusión al lugar y tiempo de la historia),
Evento inicial (referencia a un evento o problema que provoca una respuesta del personaje de la narración), Respuesta interna (información sobre el estado psicológico del personaje incluyendo emociones, deseos, sentimientos o pensamientos), Plan (mención de un verbo cognitivo que dé cuenta de una acción destinada a resolver el evento inicial), Acciones/intentos (alusión a acciones tomadas por los personajes directamente relacionadas con El), Consecuencias (referencia a una consecuencia que resuelve el problema o no resuelve el problema, relacionada con el El y expresada como una afirmación explícita), Marcadores formulaicos (mención a expresiones estandarizadas para marcar el inicio o fin de la narración), Marcadores temporales (adverbios o conectores que indiquen tiempo) y, finalmente, Conocimiento de diálogo (comentarios o afirmaciones hechos por el personaje). La corrección fue realizada por tres jueces con una fiabilidad de .91. Las diferencias fueron resueltas en discusión de pares.

Se eliminó la complicación, pues ella no era evidente en el texto fuente; se dejó de lado la 
evaluación, y se eliminó como categoría la presencia de adverbiales causales por considerárselas - en el marco de nuestro estudio - involucradas en otra variable: la complejidad sintáctica en sí, que debe ser vista como una totalidad en relación con la narrativa. Asimismo, adaptando la propuesta de Shiro (2002) complejizamos el diálogo, reconociendo subcategorías. Petersen y otros (2008) establecen tres puntajes: no diálogo: o; diálogo directo (las mariposas dijeron: ¿qué haremos?): 1; diálogo indirecto (las mariposas se preguntaron qué harían): 2. En este estudio se incluyó una categoría entre no diálogo y diálogo directo: la reproducción del enunciado sin especificar el personaje que lo emite (¿Qué haremos?), muy propia de los cuentos narrados por niños, que pareciera ser la forma más simple de referir un diálogo. Por lo demás se consideraron los puntajes de Petersen y otros (2008) aceptándose que existen elementos más relacionados con la construcción de lo narrativo que otros. A continuación, la tabla 3 presenta los criterios de la narración seleccionados y la fundamentación para asignarles puntaje.

\section{TABLA 3}

Índice de complejidad narrativa adaptado de la propuesta de Petersen y otros (2008)

\begin{tabular}{|c|c|c|c|c|}
\hline $\begin{array}{l}\text { ELEMENTO } \\
\text { NARRATIVO }\end{array}$ & o PUNTO & 1 PUNTO & 2 PUNTOS & 3 PUNTOS \\
\hline 1) Personaje: & $\begin{array}{l}\text { No lo menciona o } \\
\text { usa pronombres } \\
\text { ambiguos }\end{array}$ & $\begin{array}{l}\text { Al menos uno de } \\
\text { los personajes } \\
\text { principales, sin } \\
\text { etiquetas }\end{array}$ & $\begin{array}{l}\text { Un personaje principal } \\
\text { con etiqueta específica }\end{array}$ & $\begin{array}{l}\text { Más de un personaje } \\
\text { principal con } \\
\text { etiqueta específica }\end{array}$ \\
\hline 2) Localización: & No hay referencia & $\begin{array}{l}\text { Referencia a un lugar } \\
\text { y tiempo general }\end{array}$ & $\begin{array}{l}\text { Una o más referencias al } \\
\text { lugar y tiempo específico }\end{array}$ & \\
\hline 3) Evento inicial: & No se menciona & $\begin{array}{l}\text { Incluye al menos } \\
\text { uno, pero no existe } \\
\text { una respuesta }\end{array}$ & $\begin{array}{l}\text { Incluye al menos un } \\
\text { evento o problema que } \\
\text { elicita una respuesta } \\
\text { del personaje }\end{array}$ & $\begin{array}{l}\text { Dos o más eventos o } \\
\text { problemas distintivos } \\
\text { que elicitan repuestas } \\
\text { del personaje }\end{array}$ \\
\hline $\begin{array}{l}\text { 4) Respuesta } \\
\text { interna: }\end{array}$ & $\begin{array}{l}\text { No se da cuenta } \\
\text { de los estados } \\
\text { psicológicos del } \\
\text { personaje }\end{array}$ & $\begin{array}{l}\text { Una afirmación sobre } \\
\text { el estado psicológico } \\
\text { del personaje } \\
\text { relacionado con un } \\
\text { evento o problema }\end{array}$ & $\begin{array}{l}\text { Una o más afirmaciones } \\
\text { sobre el estado } \\
\text { psicológico del personaje } \\
\text { causalmente relacionado } \\
\text { a un evento o problema }\end{array}$ & \\
\hline 5) Plan: & $\begin{array}{l}\text { No se provee } \\
\text { ninguna afirmación } \\
\text { sobre el plan del } \\
\text { personaje para } \\
\text { resolver el evento } \\
\text { o problema }\end{array}$ & $\begin{array}{l}\text { Se incluye una } \\
\text { afirmación sobre } \\
\text { cómo el personaje } \\
\text { va a resolver la } \\
\text { complicación o } \\
\text { el problema }\end{array}$ & $\begin{array}{l}\text { Dos afirmaciones sobre } \\
\text { cómo el personaje } \\
\text { principal va a actuar } \\
\text { o resolver el evento } \\
\text { o problema }\end{array}$ & $\begin{array}{l}\text { Tres o más } \\
\text { afirmaciones sobre } \\
\text { como el personaje } \\
\text { puede actuar o resolver } \\
\text { el/los evento(s) } \\
\text { o problema(s) }\end{array}$ \\
\hline $\begin{array}{l}\text { 6) Acciones / } \\
\text { intentos: }\end{array}$ & $\begin{array}{l}\text { No hay acciones } \\
\text { tomadas por los } \\
\text { personajes }\end{array}$ & $\begin{array}{l}\text { Acciones } \\
\text { ejecutadas no } \\
\text { están directamente } \\
\text { relacionadas con El }\end{array}$ & $\begin{array}{l}\text { Intentos por el } \\
\text { personaje principal } \\
\text { están directamente } \\
\text { relacionados con El }\end{array}$ & \\
\hline 7) Consecuencias: & $\begin{array}{l}\text { No hay } \\
\text { consecuencias de las } \\
\text { acciones / intentos }\end{array}$ & Una consecuencia & Dos consecuencias & $\begin{array}{l}\text { Tres o más } \\
\text { consecuencias }\end{array}$ \\
\hline $\begin{array}{l}\text { 8) Marcadores } \\
\text { formulaicos: }\end{array}$ & $\begin{array}{l}\text { No hay marcadores } \\
\text { formulaicos }\end{array}$ & $\begin{array}{l}\text { Un marcador } \\
\text { formulaico }\end{array}$ & $\begin{array}{l}\text { Dos o más marcadores } \\
\text { formulaicos }\end{array}$ & \\
\hline
\end{tabular}




\begin{tabular}{|c|c|c|c|c|}
\hline $\begin{array}{l}\text { 9) Marcadores } \\
\text { temporales: }\end{array}$ & $\begin{array}{l}\text { No hay marcadores } \\
\text { temporales }\end{array}$ & $\begin{array}{l}\text { Un marcador } \\
\text { temporal }\end{array}$ & $\begin{array}{l}\text { Dos o más marcadores } \\
\text { temporales }\end{array}$ & \\
\hline $\begin{array}{l}\text { 10) Conocimiento } \\
\text { de diálogo: }\end{array}$ & No hay diálogo & $\begin{array}{l}\text { Diálogo sin } \\
\text { personaje emisor }\end{array}$ & $\begin{array}{l}\text { Diálogo presentado } \\
\text { en estilo directo }\end{array}$ & $\begin{array}{l}\text { Diálogo presentado } \\
\text { en estilo indirecto }\end{array}$ \\
\hline
\end{tabular}

Como puede verse, muchos de los criterios refieren a elementos constitutivos de la historia delimitados a partir de la gramática de la historia que subyace a La Mariposa Flopi (tabla 2). No obstante, no hay aquí un ánimo de observar si el sujeto reproduce la estructura del texto fuente, sino de medir el grado de elaboración que presentan los diferentes elementos en la narración que construye.

\subsubsection{Tarea de comprensión. Escala de preguntas literales e inferenciales}

La escala estuvo conformada por 8 preguntas asociadas a los elementos de la gramática de las historias; 6 de ellas fueron literales y 2 inferenciales. A continuación, en la tabla 4 se presentan las preguntas distribuidas.

\section{TABLA 4}

Relación preguntas de comprensión y elementos de la gramática de las historias

\begin{tabular}{c|c}
\hline $\begin{array}{c}\text { Establecimiento } \\
\text { de la escena / } \\
\text { protagonista }\end{array}$ & ¿De quién se habla en el cuento? \\
\hline Evento inicial & $\begin{array}{c}\text { Se habla de una mariposa. ¿Qué } \\
\text { hicieron Flopi y sus amigas? }\end{array}$ \\
\hline $\begin{array}{c}\text { Respuesta } \\
\text { interna al estado }\end{array}$ & ¿Por qué estaba enojado \\
Don Bigotes?
\end{tabular}

Las respuestas a estas preguntas fueron evaluadas en tres puntajes: o por respuesta no pertinente; 0,5 , respuesta incompleta (referencias incompletas o difusas. Ejemplo: ¿De quién se habla en el cuento? R: De ella); 1 , respuesta correcta. De esta manera el puntaje mínimo del instrumento era 0 , y el máximo, 8. Los resultados fueron analizados con el índice de Spearman y Brown y alcanzaron un índice de fiabilidad de 67.

\section{Resultados}

\subsection{Datos descriptivos}

Una vez realizadas las tareas de recopilación y análisis de datos, se obtuvieron los resultados descriptivos que se presentan en la tabla 5.

En primer lugar, podemos observar que los datos descriptivos indican un promedio de resolución de 5,5 sobre 8 en comprensión y de un 10,7 sobre 24 en producción. En ambos casos las medias y las desviaciones típicas están en valores aceptables. Además de estos datos se consideraron los porcentajes de logro que alcanzaron los sujetos en el índice de complejidad narrativa. En la tabla 6, se pueden observar los datos.

Como puede observarse, los niños alcanzan porcentajes de logro por sobre el $50 \%$ en la presentación del personaje, el evento inicial, los intentos por resolver el quiebre del evento inicial y las consecuencias, demostrando en ellos mayor elaboración. Por otra parte, los elementos en los que los sujetos evidenciaron menos del $30 \%$ de logro fueron las respuestas internas y el plan. Finalmente, en un nivel por debajo del $10 \%$ de logro están los marcadores formulaicos y el conocimiento de diálogo.

En cuanto a las preguntas de comprensión, también los sujetos evidenciaron diferencias en 


\section{TABLA 5}

Datos descriptivos

\begin{tabular}{c|c|c|c|c|c|c|c}
\multicolumn{2}{c|}{ TAREA } & TOTAL & MÍNIMO & MÁXIMO & MEDIA & $\begin{array}{c}\text { DESVIACIÓN } \\
\text { ESTÁNDAR }\end{array}$ & $\begin{array}{c}\text { COEFICIENTE } \\
\text { DE VARIACIÓN }\end{array}$ \\
\hline Comprensión & Preguntas & 8 & 3,5 & 7 & 5,5 & 1,1 & $20 \%$ \\
\hline Producción & Indicadores & 24 & 5 & 21 & 10,7 & 4,8 & $44 \%$ \\
\hline
\end{tabular}

\section{TABLA 6}

Porcentajes de logro en el índice de complejidad narrativa

\begin{tabular}{c|c} 
ELEMENTO NARRATIVO & PORCENTAJE DE LOGRO \\
\hline Personaje & 55 \\
\hline Localización & 45 \\
\hline Evento inicial & 62 \\
\hline Respuesta interna & 28 \\
\hline Plan & 21 \\
\hline Acciones/intentos & 89 \\
\hline Consecuencias & 72 \\
\hline Marc. form. & 4 \\
\hline Marc. temp. & 43 \\
\hline Con. de diálogo & 8 \\
\hline
\end{tabular}

el porcentaje de logro, evidenciándose una mayor comprensión de ciertos aspectos de la narración. En la tabla 7 se presentan estos resultados.

Como puede observarse, los niños alcanzan porcentajes de logro por sobre el $50 \%$ en casi todas las respuestas, menos el primer evento inicial (35) y la primera respuesta interna (48), que - de todas formas - evidencia un porcentaje de comprensión del cuento por encima del de complejidad narrativa del recontado. La presentación del personaje, los intentos por resolver el quiebre del evento inicial y las consecuencias parecen tener los porcentajes más altos de respuesta, a la vez que son los más elaborados en el índice de complejidad narrativa. Sin embargo, es necesario notar que el porcentaje de la respuesta interna, si bien en el primer evento está por debajo de $50 \%$, en el segundo llega al $96 \%$ de
TABLA 7

Porcentaje de logro en preguntas de comprensión

\begin{tabular}{l|c}
\multicolumn{1}{c|}{\begin{tabular}{c}
\multicolumn{1}{c}{$\begin{array}{c}\text { MREGUNTAS DE COMPRENSIÓN } \\
\text { DE LA HISTORIA }\end{array}$} \\
PORCENTAJE \\
DE LOGRO
\end{tabular}} \\
$\begin{array}{l}\text { ¿De quién se habla en el cuento? } \\
\text { establecimiento de la }\end{array}$ & 82 \\
\hline $\begin{array}{l}\text { ¿Qué hicieron Flopi y sus amigas? } \\
\text { Evento inicial }\end{array}$ & 35 \\
\hline $\begin{array}{l}\text { ¿Por qué estaba enojado Don Bigotes? } \\
\text { Respuesta interna }\end{array}$ & 48 \\
\hline $\begin{array}{l}\text { ¿Qué pasó después? } \\
\text { Plan e intento }\end{array}$ & 65 \\
\hline $\begin{array}{l}\text { ¿Qué problema tuvieron? } \\
\text { Consecuencia evento inicial }\end{array}$ & 74 \\
\hline $\begin{array}{l}\text { ¿Cómo crees que se sintió Flopi? } \\
\text { Respuesta interna }\end{array}$ & 96 \\
\hline $\begin{array}{l}\text { ¿Qué pasó al final? } \\
\text { Plan, intento y desenlace }\end{array}$ & 80 \\
\hline \begin{tabular}{l} 
¿Qué aprendieron? \\
\hline
\end{tabular} & 72 \\
\hline
\end{tabular}

logro, una gran diferencia si se observa que en el índice de complejidad narrativa del recontado los niños no lograron más que el $28 \%$ del dominio de esta categoría.

\subsection{Datos inferenciales}

En relación a la hipótesis planteada en este estudio respecto de la relativa independencia de las medidas relacionadas con la comprensión oral y la capacidad de producción narrativa, se realizaron cálculos inferenciales que permitieran determinar la asociación entre ambas medidas. Para los cálculos se aplicaron dos coefi- 
cientes de correlación no paramétricos: Kendall y Spearman, cuyos valores fluctúan entre uno y menos uno. Los datos se representan en la figura 1 y en la tabla 8.

\section{FIGURA 1}

Diagrama de dispersión entre la capacidad de comprensión y la capacidad de narración

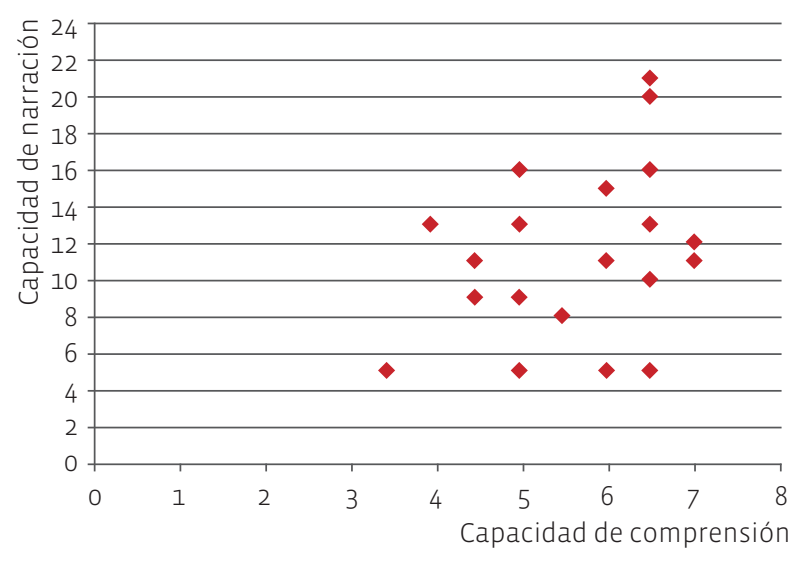

\section{TABLA 8}

Medidas de asociación no paramétricas entre la capacidad de comprensión y la capacidad de narración

\begin{tabular}{c|c|c}
$\begin{array}{c}\text { MEDIDA DE } \\
\text { ASOCIACIÓN }\end{array}$ & COEFICIENTES & VALOR-P \\
\hline Kendall & 0,263 & 0,108 \\
\hline Spearman & 0,363 & 0,089 \\
\hline
\end{tabular}

Como puede observarse en ambos índices el valor P está por sobre 05, lo que indicaría que no hay una correlación entre la prueba que mide la comprensión que los niños tenían del relato y la calidad que lograban al recontarlo otra vez. Por otra parte, como un modo de confirmar el no rechazo de la hipótesis, se realizó una selección de 10 participantes con igual capacidad de comprensión (6 puntos, similar a la media) y se observó la capacidad de narración. La figura 2 muestra los resultados.

\section{FIGURA 2}

Capacidad de narración de 10 niños con igual capacidad de comprensión

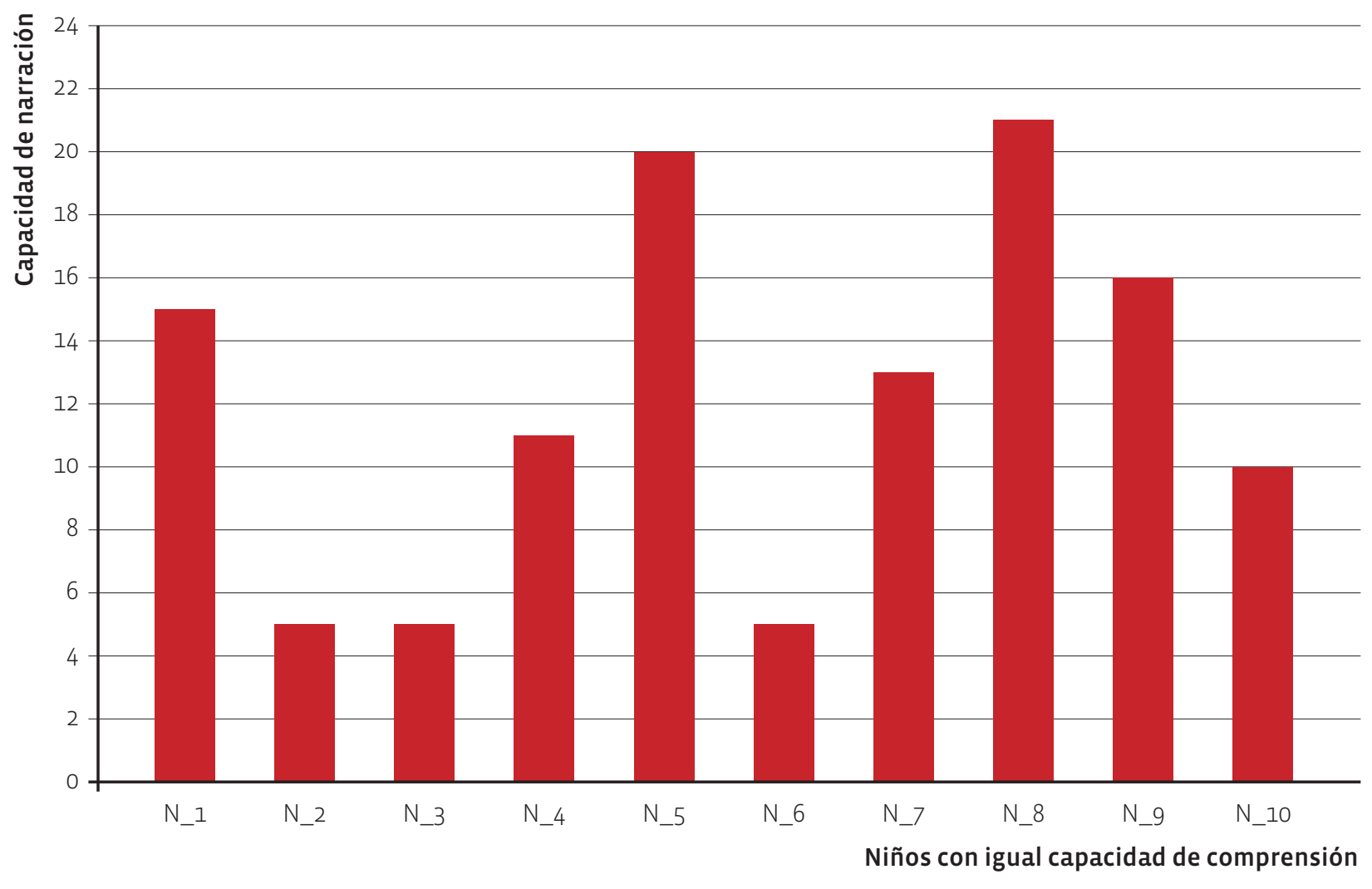


Como se puede observar, la capacidad de comprensión de los participantes no arroja una regularidad que permita asumir correlación, puesto que las puntuaciones varían de 5 a 21 puntos (sujetos 2 y 3 en relación con los sujetos 5 y 8). En conclusión, podemos afirmar que los niños que comprenden no necesariamente son capaces de narrar, cuando se evalúa la capacidad de comprensión, a través del recontado con las condiciones ya mencionadas, y la producción, a través de un índice independiente de lo mediatizado por el recuerdo.

\section{Discusión}

La problemática planteada inicialmente expone la necesidad de abordar el recontado como una tarea de doble faz, midiendo la dimensión de producción oral mediatizada por la comprensión de un estímulo inicial (como es el caso de un cuento). El nudo crítico a abordar corresponde a la posibilidad de medir la independencia de la capacidad de comprensión de aquella involucrada en la de producción. Tomando esto en cuenta, en esta discusión abordamos tres ámbitos: la tarea de recontado propuesta y sus alcances; la característica de las medidas propuestas para comprensión y producción, y, finalmente, cómo ello explica los resultados no correlacionales entre ambas variables.

Ya se ha podido observar que la tarea privilegiada en este estudio es la de recontado, a la que se le dio un formato similar a la tercera de las expuestas en el estudio de Skehan y Foster (1999): (i) visualización de un video con una historia completa; (ii) revisualización sin sonido, y (iii) narración simultánea con el formato visual. En este estudio, el niño, en vez de ver un video, ve las imágenes estáticas del cuento en un formato de libro que puede manipular libremente. La elección del formato obedeció al deseo de potenciar la mayor riqueza lingüística en la producción, disminuyendo el efecto del recuerdo, por un lado, y de la tensión que provocaría narrar la historia al ritmo de un video, por otro. Además se tuvo en cuenta el carácter multimodal del texto fuente, diseñando las imágenes de acuerdo a la gramática visual de Kress y Van Leeuwen (1996, 2001). Respecto de esto último, creemos que ha sido posible ver una potenciación semiótica entre el artefacto visual y el verbal que, de alguna manera, ha propiciado la mayor riqueza del habla del niño, en tanto descarga cognitiva de la tarea, al poder detenerse en las imágenes que contienen parte de la historia. En otras palabras, la tarea tanto en sus materiales como en sus condiciones de diseño buscó que el mayor o menor dominio que demostrara el niño al narrar su historia reflejara su habilidad y no el nivel de dificultad que implica elicitarla.

La medida de producción, llamada también medidas de criterio por sus autores originales, Petersen y otros (2008), permitió — de alguna manera- medir la riqueza de la narración infantil, utilizando un criterio más acucioso que el mero conteo de presencia y ausencia de partes de la narración. Por los resultados, ha sido posible colegir varias conclusiones. Por una parte, se observó que, en la narrativa, la mayor elaboración se relaciona con la presentación del personaje, los intentos y las consecuencias. Es decir, como lo señala Owens (1991), la agentividad y las acciones en el tiempo parecieran ser más evidentes para los niños. Sin embargo, cuando se refiere a las emociones de los personajes o lo que Bocaz (1996) Ilamaría el paisaje de la conciencia, pueden indicarse diferencias entre la elicitación y la elaboración de este elemento en el relato creado por los niños y el reporte inducido por preguntas. Esto permitiría señalar que las tareas de recontado posibilitan dar cuenta de la comprensión tanto de los agentes como de las acciones en ideas-unidad. No obstante, no posibilita dar cuenta de en qué medida el sujeto comprende los estados internos que motivan a los personajes, lo que se obtiene a través de preguntas directas. Esta evidencia marca, a nuestro juicio, una distancia entre ambas tareas (comprensión y producción) al indicar que ciertos elementos propios de la historia no son elicitados si no es por indicación directa del evaluador, lo que im- 
plica un nivel de comprensión no evidenciable a través de la producción oral, contabilizando, por ejemplo, las proposiciones presentes en ella. Asimismo, es necesario llamar la atención acerca del logro de un $96 \%$ respecto de la pregunta que indagaba acerca de la respuesta interna del segundo episodio (¿Cómo se siente Flopi?), la cual parece haber sido influenciada por un acercamiento de las ilustraciones al personaje de acuerdo a las propuestas de Kress y Van Leeuwen (1996). En otras palabras, considerar el potencial semiótico de las imágenes, que van más allá del acompañamiento de las palabras, parece estar favoreciendo la comprensión que los niños realizan de la narración fuente.

En cuanto al evento inicial, si bien se observa una cierta complejidad por parte de los niños, es interesante que casi no se reporta en las preguntas de comprensión. Así, muchos niños no pueden dar cuenta de qué fue lo que motivó la acción del antagonista (¿Qué hicieron las mariposas que Don Bigotes se molestó?). Esto es coincidente con lo planteado por Pavez y otros (2008), quienes indican que, en niños de 4 a 5 años, la comprensión de la trama es débil y no se construye a partir de las metas ni atributos del personaje ni aun inducido por preguntas.

A pesar de todos los méritos del índice de complejidad narrativa, creemos que este instrumento debe afinarse en algunos de sus aspectos (por ejemplo, el de evaluación, que no se consideró en este estudio) y su incrementalidad debería ponerse a prueba con niños de diversas edades y nivel de instrucción, para observar si los criterios seleccionados y las pautas para evaluarlos están realmente reflejando un dominio de lo narrativo. Otro tema importante refiere a que este instrumento no puede ser utilizado indistintamente para cualquier narración, sino que siempre debe ser ad hoc a una fuente (ya sea visual, verbal o audiovisual) respecto de la cual considerar la narración del niño.

Finalmente, cabe aquí destacar cómo la tarea de recontado - en las condiciones ade- cuadas - permite una medición acuciosa de la productividad narrativa de los niños, más allá de la comprensión inicial del estímulo. Con esto se concluye que no es lo mismo comprender un cuento que demostrar dominio narrativo a la hora de reproducirlo. La fluidez que evidencian los niños al momento de narrar sus cuentos parece depender de otros factores distintos de las condiciones de la tarea. En este sentido, puede sostenerse que el recontado es un recurso valioso para estudiar el habla infantil.

\section{Bibliografía citada}

Acosta, Víctor, Nayra González y Carla LoRenzo, 2011: "Un análisis cualitativo de la estructura episódica, los recursos cohesivos y la diversidad léxica en la narrativa de alumnado con Trastorno Específico del Lenguaje", Revista de Psicologia, Ciències de l'Educació i de l'Esport 28, 143-159.

Balason, Denisse y Christine Dollaghan, 2002: "Grammatical morpheme production in fouryear-old children”, Journal of Speech, Language, and Hearing Research 45, 961-969.

Bocaz, Aura, 1996: "El paisaje de la conciencia en las producciones de narraciones infantiles", Lenguas modernas 23, 49-68.

Botting, Nicola, 2002: "Narrative as a tool for the assessment of linguistic and pragmatic impairments", Child Language Teaching and Therapy 18, 1-21.

Brown, Roger, 1973: A first language, Cambridge, MA: Harvard University Press.

Cavalcante, P. A. y P. P. Mandra, 2010: "Oral narratives of children with typical language development", Pró-Fono Revista de Atualização Científica 22 (4), 391-396 [http://www.scielo. br/scielo.php?script=sci_arttext\&pid=S010456872010000400005\&lng=en\&tlng=en.10.1590/ S0104-56872010000400005, fecha de consulta: 25 de julio, 2013] 
Eisenbeiss, Sonja, 2010: "Production methods in language acquisition research" en E. BLom y S. UNsWORTH (eds): Experimental methods in language acquisition research, Amsterdam: John Benjamins Publishing Company, 11-34.

García, Ricardo, Andrea Bustos y Emilio Sánchez, en prensa: "The contribution of knowledge about anaphors, organizational signals, and refutations to Reading comprehension", Journal of Research in Reading.

Gazella, Jamie e Ida J. Stockman, 2003: "Children's story retelling under different modality and task conditions: implications for standardizing language sampling procedures", American Journal of Speech Language Pathology 12 (1), 61-72.

Gillam, Ronald y Nils Pearson, 2004: The Test of Narrative Language, Austin: TX, Pro-Ed.

Guerrero, Silvana, 2011: "Análisis sociolingüístico de las diferencias de género en los patrones narrativos de historias de experiencia personal en el habla juvenil de Santiago de Chile", Boletín de Filología 46 (2), 85-106.

Isbell, Rebecca, Joseph Sobol, Liane Lindauer y April LOWRANCE, 2004: "The Effects of Storytelling and Story Reading on the Oral Language Complexity and Story Comprehension of Young Children", Early Childhood Education Journal, vol. 32, no. 3, 157-163.

Justice, Laura, Ryan Bowles, Joan Kaderavek, Teresa Ukrainetz, Sarita Eisenberg y Ronald Gillam, 2006: "The Index of Narrative Microstructure: A Clinical Tool for Analyzing School-Age Children's Narrative Performances", American Journal of SpeechLanguage Pathology, vol. 15, 177-191.

Kress, Gunther y Teun van Leeuwen, 1996: Visual grammar, Londres: Equinox.

Kress, Gunther y Teun van LeEuwen, 2001: Multimodal Discourse - The Modes and Media of Contemporary Communication, Londres: Arnold.

LABOV, William y Joshua WaletZky, 1967: "Narrative analysis" en June Helm (ed.): Essays on the verbal and visual arts, Seattle: University of Washington Press, 12-44.

León, José Antonio y Álvaro MarchesI, 1987: "La influencia de variables cognitivas en el recuerdo de cuentos y su valoración en función de la edad", Infancia y Aprendizaje 37, 19-31.

Luque, Juan Luis, Juan Antonio García Madruga, Jesús Ignacio Martín Cordero y Carlos Santa Maria, 1996: "El análisis de protocolos de recuerdo libre: problemas metodológicos e implicaciones educativas", Revista de Psicología General y Aplicada 49 (2), 321-336.

McCabe, Allyssa y Lynn Bliss, 2004: "Narratives from Spanish-speaking children with impaired and typical language development", Imagination, Cognition and Personality 24, 331-346.

Mandel Morrow, Lesley, 1986: "Effects of structural guidance in story retelling on children's dictation of original stories", Journal of Reading Behavior XVIII, no. 2.

Meyer, Bonnie, 1985: "Prose analysis: purposes, procedures and problems" en B. K. BRITTOn y J. B. Black (eds.): Understanding expository text. A theoretical and práctical handbook for analizing explanatory text, Hillsdale: Lawrence Erlbaum.

Owens, Robert E., 1991: Language disorders: A functional approach to assessment and intervention, New York: Merrill/Macmillan.

Pavez, María, Carmen Coloma y Mariangela MagGIolo, 2008: El desarrollo narrativo en niños. Una propuesta práctica para la evaluación y la intervención en niños con trastorno del lenguaje, Barcelona: Ars Medica.

Petersen, Douglas, Sandra Gillam y Ronald Gillam, 2008: "Emerging Procedures in Narrative Assessment The Index of Narrative Complexity", Topics in Language Disorders 28, 2, 115-130.

Peterson, Carole y Allyson McCabe, 1983: Developmental psycholinguistics: Three ways of looking at a child's narrative, New York: Plenum Press. 
Reese, Elaine, Alison Sparks y Sebastian Suggate, 2012: "Assessing children's narratives" en E. Hoff: Research methods in child languaje. A practical guide, New York, NY: Wiley-Balckwell, 133-148.

Reilly, Judy, Molly Losch, Ursula Bellugi y Beverly WulfECK, 2004: "Frog, where are you? Narratives in children with specific language impairment, early focal brain injury, and Williams syndrome", Brain and Language 88, 229-247.

SchneIDER, Phyllis, 1996: "Effects of Pictures Versus Orally Presented Stories on Story Retellings by Children With Language Impairment", American Journal of Speech-Language Pathology 5, 86-96.

SHESkIN, David, 2000: Handbook of parametric and nonparametric statistical procedures, London: Chapman \& Hall / CRC Taylor \& Francis Group.

SHIRo, Martha, 2002: "Representación del yo y del otro en la narrativa de adultos caraqueños" en G. Sото (ed.): Actas del III Coloquio Internacional del ALED 5 al 9 de abril 1999, Santiago de Chile: Universidad de Chile y Universidad Católica de Chile.

Silva, María Luisa, Verónica Sánchez Abch y Ana María Borzone, 2010: "Subordinated clauses usage and assessment of syntactic maturity: A comparison of oral and written retellings in beginning writers", Journal of Writing Research 2 (1), 47-64.

SKeHAN, Peter y Pauline Foster, 1999: "The Influence of Task Structure and Processing Conditions on Narrative Retellings", Language Learning 49:1, 93-120.

Stein, Nancy y Christine Glenn, 1979: "An analysis of story comprehension in elementary school children" en R. O. Freedle (ed.): Advances in discourse processes: New directions in discourse processing, vol. 2, Norwood, NJ: Ablex.

SLOBIN, Dan, 2004: "The many ways to search for a frog: Linguistic typology and the expression of motion events" en S. Strömqvist y L. Verhoeven (eds.): Relating events in narrative, vol. 2: Typolo- gical and contextual perspectives, Mahwah, NJ: Lawrence Erlbaum Associates, 219-257.

Van DIJK, Teun y Walter KInTSCH, 1998: Strategies of Discourse Comprehension, New York: Academic Press.

Westerveld, Marleen, 2011: “Children's Story Retelling and Comprehension. Performance under Different Task Conditions", ASHA (American Speech-language Hearing Association) Convention Poster's, San Diego EEUU. 